\title{
Treatment outcomes for patients with Middle Eastern Respiratory Syndrome Coronavirus (MERS CoV) infection at a coronavirus referral center in the Kingdom of Saudi Arabia
}

\author{
Mohammed Al Ghamdi', Khalid M. Alghamdi', Yasmeen Ghandoora', Ameera Alzahrani', Fatmah Salah', \\ Abdulmoatani Alsulami', Mayada F. Bawayan ${ }^{1}$, Dhananjay Vaidya ${ }^{2}$, Trish M. Perl ${ }^{3}$ and Geeta Sood ${ }^{3 *}$
}

\begin{abstract}
Background: Middle Eastern Respiratory Syndrome coronavirus (MERS-CoV) is a poorly understood disease with no known treatments. We describe the clinical features and treatment outcomes of patients with laboratory confirmed MERS-CoV at a regional referral center in the Kingdom of Saudi Arabia.

Methods: In 2014, a retrospective chart review was performed on patients with a laboratory confirmed diagnosis of MERS-CoV to determine clinical and treatment characteristics associated with death. Confounding was evaluated and a multivariate logistic regression was performed to assess the independent effect of treatments administered.

Results: Fifty-one patients had an overall mortality of $37 \%$. Most patients were male (78 \%) with a mean age of 54 years. Almost a quarter of the patients were healthcare workers (23.5 \%) and $41 \%$ had a known exposure to another person with MERS-CoV. Survival was associated with male gender, working as a healthcare worker, history of hypertension, vomiting on admission, elevated respiratory rate, abnormal lung exam, elevated alanine transaminase (ALT), clearance of MERS-CoV on repeat PCR polymerase chain reaction (PCR) testing, and mycophenolate mofetil treatment. Survival was reduced in the presence of coronary artery disease, hypotension, hypoxemia, CXR (chest X-ray) abnormalities, leukocytosis, creatinine $>1.5 \mathrm{mg} / \mathrm{dL}$, thrombocytopenia, anemia, and renal failure. In a multivariate analysis of treatments administered, severity of illness was the greatest predictor of reduced survival.
\end{abstract}

Conclusions: Care for patients with MERS-CoV remains a challenge. In this retrospective cohort, interferon beta and mycophenolate mofetil treatment were predictors of increased survival in the univariate analysis. Severity of illness was the greatest predictor of reduced survival in the multivariate analysis. Larger randomized trials are needed to better evaluate the efficacy of these treatment regimens for MERS-CoV.

Keywords: Middle Eastern Respiratory Syndrome coronavirus, MERS CoV, Coronavirus, Survival, Treatment outcome

\footnotetext{
* Correspondence: gsood1@jhmi.edu

${ }^{3}$ Department of Internal Medicine, Division of Infectious Diseases, The Johns

Hopkins University, School of Medicine, Baltimore, 21224 Maryland, USA

Full list of author information is available at the end of the article
} 


\section{Background}

Coronaviruses cause a spectrum of illness from asymptomatic disease to respiratory failure. Early reports of coronavirus infections suggested that most infections were mild until the 2003 SARS epidemic that was associated with significant morbidity and mortality [1]. In September 2012, a novel coronavirus was identified in a 60-year old man in Saudi Arabia [2]. A second case was identified in a Qatari patient hospitalized in the United Kingdom [3]. The two coronaviruses were genetically identical and similar to isolates obtained from bats [4]. In July 2013, the coronavirus study group named this new virus Middle East respiratory syndrome coronavirus (MERS-CoV) [5].

As of December 21, 2015, there have been 1625 cases worldwide with 586 deaths [6]. The epidemiology and clinical manifestations of this disease have described a spectrum of illness from asymptomatic infection to severe respiratory failure and death. The overall mortality rate remains at $37 \%$ [7-15]. Importantly, there are no known effective treatments. In 2014 there was an increase in MERS-CoV cases reported from the Jeddah region of Saudi Arabia. To describe the changing epidemiology and outcomes, we report the clinical features and treatment outcomes of patients admitted to a regional referral hospital in Jeddah, Saudi Arabia.

\section{Methods}

\section{Study setting and participants}

King Fahd General Hospital is an 800-bed hospital in Jeddah, Kingdom of Saudi Arabia and is a regional coronavirus referral center. There are 36 ICU beds and one Infectious Disease physician that serves the hospital. Between January through December 2014, all patients admitted or transferred to King Fahd Hospital with a positive MERS coronavirus PCR from clinical nasal swabs or nasopharyngeal aspirates were included.

\section{Molecular methods}

All PCR testing was performed at the Ministry of Health Regional Lab in Jeddah. The MagNa Pure Compact/ MagNa Pure 96 (Roche) automated system was used to extract RNA from samples. Primers and probes for upE and Orf 1a targets of MERS-CoV were used from TIB MOLBIOL (Germany) along with Master Mix from Roche for the Light Cycler 480 II (Roche) were used to amplify upE and Orf 1a gene targets. Samples that tested positive for both upE and Orf 1a gene targets with a cycle threshold time of less than 37 were considered confirmed cases. Positive and negative controls were used to monitor the amplification process \& to check for any inhibition of amplification.

\section{Case review and definitions}

Medical charts for all patients were reviewed and data abstracted on standardized data collection forms by an infectious disease trained physician. Demographic, clinical and laboratory data were entered into a database. To understand the epidemiology, age was categorized as <30, 30-60 and $>60$. Hypotension was defined as blood pressure $<90 / 60 \mathrm{~mm} \mathrm{Hg}$, tachypnea as a respiratory rate greater than 16 , hypoxia as an oxygen saturation $<90 \%$, thrombocytopenia as platelets $<150,000 /$ cubic millimeter, leukopenia was defined as a white blood cell count $<5000$ cells/cubic millimeter and leukocytosis as a white blood cell count $>10,000$ cells/ cubic millimeter. Renal insufficiency was defined as a creatinine $>1.5 \mathrm{mg} / \mathrm{dL}$. Liver function abnormalities were defined as a lactate dehydrogenase $(\mathrm{LDH})>300$ U/liter, alanine transaminase $(\mathrm{ALT})>50 \mathrm{U} /$ Liter and aspartate aminotransferase (AST) $>40$ U/Liter. Immunosuppression was defined as AIDS, history of organ transplant, neutropenia, known malignancy, taking immunosuppressive medication and congenital immunodeficiency. Pregnancy was considered an immunosuppressed state.

A modified Acute Physiologic and Chronic Health Evaluation (APACHE 2) score was calculated using age, temperature, mean arterial blood pressure, respiratory rate, potassium, creatinine, acute renal failure, and comorbid conditions to estimate severity of illness [16]. $\mathrm{PaO} 2$ was estimated using pulse oximetry oxygen saturation results and hematocrit was calculated by multiplying the hemoglobin times three.

\section{Statistical analysis}

All statistical analyses were performed using Stata software (Version 13.1, College Station, TX). The percent distribution of clinical variables among patients who survived and those who died were compared using the Fisher exact test. A multivariate logistic regression was done on treatments administered and severity of illness to determine which treatments were associated with survival. Mycophenolate mofetil was not included in this logistic regression analysis because $100 \%$ of patients receiving mycophenolate mofetil survived. The association between severity of illness and treatments administered was assessed by performing a linear regression of treatments administered onto the modified APACHE 2 score.

\section{Results}

\section{Demographic and exposure characteristics}

There were a total of 51 cases, thirty patients $(58.8 \%)$ of whom were Saudi nationals, and 21 (41.2\%) were foreign nationals. The median age was 54 years old (IQR 36.5-58). Most were male $(n=40,78.4 \%)$. Twenty-one 
patients (41.2\%) had exposure to a known patient with MERS coronavirus and $12(23.5 \%)$ were healthcare workers. None of the patients had animal exposure. Two patients (3.9\%) were on pilgrimage to Mecca.

Overall, $71 \%$ of patient had at least one co-morbid condition. Seventeen patients had diabetes (33.3\%), 25 had hypertension (49\%), 14 (27.5\%) had end stage renal disease, eight (15.7 \%) had coronary artery disease and six $(11.8 \%)$ patients were immunosuppressed, two of whom were pregnant.

\section{Clinical and laboratory findings}

Forty-nine patients (96\%) had documented fever, 41 (80.4\%) had cough, and 46 (90\%) reported shortness of breath. Thirteen patients $(25.5 \%)$ had diarrhea, 12 (23.5 \%) had vomiting and 5 (9.8\%) complained of sore throat. The clinical findings on presentation included eight patients $(15.7 \%)$ with hypotension, 39 (76.9 \%) with tachypnea and 17 patients (33\%) with hypoxia. As previously reported, laboratory findings were nonspecific. Fourteen patients (27.5\%) were anemic, 15 (29.4\%) were thrombocytopenic, and 28 (54.9\%) were leukopenic. Many patients had liver function abnormalities. Twenty-three $(45.1 \%)$ had elevated ALT and 35 $(68.6 \%)$ had an elevated AST. Thirty-two patients (62.8\%) had an elevated LDH, 24 patients (47.1\%) had an elevated CK and 21 patients (41.2 \%) had an elevated creatinine.

\section{Treatments administered}

Patients received a variety of novel treatments including immunosuppressants and antivirals. Forty-two (82.4 \%) patients received broad-spectrum antibiotics and five $(9.8 \%)$ received hydrocortisone. Thirty one patients received antiviral treatment. Twenty-three patients (45.1\%) were treated with interferon beta, eight (15.7\%) were treated with interferon alpha. A variety of anti-viral combinations were used. Eight patients (15.7 \%) received mycophenolate mofetil, seven of these patients received it in combination with interferon beta. Nineteen (37.3\%) patients required intensive care unit (ICU) care, and 10 patients received extracorporeal membrane oxygenation (ECMO). All patients treated in the ICU and all patients receiving ECMO died.

\section{Univariable association of demographic, clinical features and treatment with death}

In this recent cohort, when comparing survivors to nonsurvivors, survival was associated with male gender, vomiting on admission, elevated respiratory rate, abnormal lung exam on physical exam, working as a healthcare worker, history of hypertension, elevated ALT, clearance of MERS CoV on repeat PCR testing, and receiving mycophenolate mofetil or beta interferon (Table 1). In contrast, markers of severe disease like hypotension, hypoxemia, chest radiographic abnormalities, leukocytosis, elevated creatinine, thrombocytopenia, anemia, renal failure were associated with death.

\section{Treatments given}

Treatments given were based as indicated based on the clinical assessment of the infectious disease consult team. Thirty-one patients received antivirals, ribavirin or alpha or beta interferon, and 13 patients received immunosuppressive medication. Most patients received a combination of alpha interferon and ribavirin (5, 9.8\%), beta interferon and ribavirin $(10,19.5 \%)$ or beta interferon alone (11, $21.6 \%)$. Two patients received alpha interferon alone (3.9\%). Eight patients received mycophenolate mofetil (15.7\%) and seven of them received this in combination with beta-interferon. Five patients received hydrocortisone; two in combination with beta interferon and ribavirin and 3 in combination with alpha interferon and ribavirin. All eight patients given mycophenolate mofetil survived therefore mycophenolate mofetil could not be evaluated in this model.

\section{Impact of treatments}

While the results of the univariable analysis demonstrated improved survival in patients treated with betainterferon and mycophenolate mofetil, the multivariable analysis which included a marker of severity of illness, demonstrated a strong association between severity of illness and reduced survival, and no association between treatment with beta interferon and survival. Mycophenolate mofetil was not evaluable in this model (Table 2). In analyzing the relationship between severity of illness and treatments administered, beta interferon and mycophenolate mofetil were given to less severely ill patients (Table 3)

\section{Discussion}

MERS-CoV is an emerging disease for which the initial epidemiology has been described, but in-depth clinical studies and the role of therapy in incompletely understood. While the clinical features for MERS-CoV have been described in several large case series [6-14], there is a paucity of literature on therapy. Our results from a relatively large number of patients demonstrate similar clinical features and mortality to previous studies [6-14]. In our cohort, treatment with beta interferon and mycophenolate mofetil may be predictive of survival, but the greatest predictor of survival is the severity of illness on presentation.

Improved diagnostics have demonstrated an expanded spectrum of disease that includes less severe cases than previously reported. We now understand that MERS$\mathrm{CoV}$ causes an acute respiratory disease syndrome and 
Table 1 Predictors for poor outcome among 51 MERS CoV cases in KSA 2014

\begin{tabular}{|c|c|c|c|c|}
\hline & Total & Survival & Death & $P$ value \\
\hline \multicolumn{5}{|l|}{ Demographics and Epidemiology } \\
\hline Age $<=30$ & $7(13.7 \%)$ & $6(85.7 \%)$ & $1(14.29 \%)$ & \multirow[t]{3}{*}{0.187} \\
\hline Age 31-60 & $32(62.8 \%)$ & $22(64.7 \%)$ & $12(35.3 \%)$ & \\
\hline Age $>60$ & $10(19.6 \%)$ & $4(40 \%)$ & $6(60 \%)$ & \\
\hline Gender - male & $40(78.4 \%)$ & $22(55 \%)$ & $18(45 \%)$ & 0.037 \\
\hline Known MERS exposure & $21(41.2 \%)$ & $12(57.1 \%)$ & $9(42.9 \%)$ & 0.563 \\
\hline Healthcare worker & $12(23.5 \%)$ & $11(91.7 \%)$ & $1(8.3 \%)$ & 0.020 \\
\hline Umrah patient & $2(3.9 \%)$ & $2(100 \%)$ & $0(0 \%)$ & 0.523 \\
\hline \multicolumn{5}{|l|}{ Co-morbid conditions } \\
\hline Diabetes & $17(33.3 \%)$ & $9(52.9 \%)$ & $8(47.1 \%)$ & 0.365 \\
\hline Hypertension & $25(49 \%)$ & $10(40 \%)$ & $15(60 \%)$ & 0.001 \\
\hline End stage renal disease & $14(27.5 \%)$ & $6(42.9 \%)$ & $8(57.1 \%)$ & 0.106 \\
\hline Coronary artery disease & $8(15.7 \%)$ & $3(37.5 \%)$ & $5(62.5 \%)$ & 0.131 \\
\hline Immunosuppression & $6(11.8 \%)$ & $5(83.3 \%)$ & $1(16.7 \%)$ & 0.392 \\
\hline \multicolumn{5}{|l|}{ Signs and Symptoms } \\
\hline Runny nose & $6(11.8 \%)$ & $5(83.3 \%)$ & $1(16.67 \%)$ & 0.392 \\
\hline Cough & $41(80.4 \%)$ & $26(63.4 \%)$ & $15(36.6 \%)$ & 1.000 \\
\hline Diarrhea & $13(25.5 \%)$ & $11(84.6 \%)$ & $2(15.4 \%)$ & 0.096 \\
\hline Vomiting & $12(23.5 \%)$ & $11(91.7 \%)$ & $1(8.3 \%)$ & 0.020 \\
\hline Sore throat & $5(9.8 \%)$ & $3(60 \%)$ & $2(40 \%)$ & 1.000 \\
\hline Abnormal lung exam & $20(39.2 \%)$ & 17 (85 \%) & $3(15 \%)$ & 0.016 \\
\hline Subjective fever & 49 (96.1\%) & $30(61.2 \%)$ & $19(38.8 \%)$ & 0.523 \\
\hline Temperature $>38$ Celsius & $25(49 \%)$ & $13(52 \%)$ & $12(48 \%)$ & 0.153 \\
\hline Respiratory rate $>16$ & $39(76.5 \%)$ & $21(53.9 \%)$ & $18(46.2 \%)$ & 0.020 \\
\hline Blood pressure $<90 / 60 \mathrm{~mm} \mathrm{Hg}$ & $8(15.7 \%)$ & $0(0 \%)$ & $8(100 \%)$ & 0.000 \\
\hline Oxygen saturation < $90 \%$ & $17(33.3 \%)$ & $4(23.5 \%)$ & $13(76.5 \%)$ & 0.000 \\
\hline \multicolumn{5}{|l|}{ Laboratory findings } \\
\hline Hemoglobin < $10 \mathrm{~g} / \mathrm{dL}$ & $14(27.5 \%)$ & $4(28.6 \%)$ & $10(71.4 \%)$ & 0.003 \\
\hline White Blood cell count $<5,000$ cells $/ \mathrm{mm}^{3}$ & $28(54.9 \%)$ & $21(75 \%)$ & $7(25 \%)$ & 0.080 \\
\hline White Blood cell count $>10,000$ cells $/ \mathrm{mm}^{3}$ & $9(17.6 \%)$ & $2(22.2 \%)$ & $7(77.8 \%)$ & 0.009 \\
\hline Platelets < 150,000/mm3 & $15(29.4 \%)$ & $9(60 \%)$ & $6(40 \%)$ & 1.000 \\
\hline $\mathrm{ALT}>50 \mathrm{U} / \mathrm{L}$ & $23(45.1 \%)$ & $14(61 \%)$ & 9 (39.1\%) & 1.000 \\
\hline AST $>40 \mathrm{U} / \mathrm{L}$ & $35(68.6 \%)$ & $18(51.4 \%)$ & $17(48.6 \%)$ & 0.015 \\
\hline $\mathrm{LDH}>300 \mathrm{U} / \mathrm{L}$ & $32(62.7 \%)$ & $18(56.3 \%)$ & $14(43.8 \%)$ & 0.247 \\
\hline Creatinine $>1.5 \mathrm{mg} / \mathrm{dL}$ & $21(41.2 \%)$ & $8(38.1 \%)$ & $13(61.9 \%)$ & 0.003 \\
\hline CK> $200 \mathrm{U} / \mathrm{L}$ & 24 (47.1\%) & $13(54.2 \%)$ & $11(45.8 \%)$ & 0.261 \\
\hline Potassium > $4.5 \mathrm{mmol} / \mathrm{L}$ & $17(33.3 \%)$ & $8(47.1 \%)$ & $9(52.9 \%)$ & 0.131 \\
\hline Negative repeat PCR swab & $31(60.8 \%)$ & $30(96.8 \%)$ & $1(3.23 \%)$ & 0.000 \\
\hline \multicolumn{5}{|l|}{ Radiology } \\
\hline CXR - Right upper lobe infiltrate & $17(33.3 \%)$ & $5(29.4 \%)$ & $12(70.6 \%)$ & 0.001 \\
\hline CXR - Right lower lobe infiltrate & $32(62.7 \%)$ & $13(40.6 \%)$ & $19(59.4 \%)$ & 0.000 \\
\hline CXR - Left upper lobe infiltrate & $19(37.3 \%)$ & 7 (36.8 \%) & $12(63.2 \%)$ & 0.006 \\
\hline CXR - Left lower lobe infiltrate & $31(60.8 \%)$ & $13(41.9 \%)$ & $18(58.1 \%)$ & 0.000 \\
\hline
\end{tabular}


Table 1 Predictors for poor outcome among 51 MERS CoV cases in KSA 2014 (Continued)

\begin{tabular}{|c|c|c|c|c|}
\hline \multicolumn{5}{|l|}{ Treatments administered } \\
\hline Interferon beta & $23(45.1 \%)$ & $18(78.3 \%)$ & $5(21.7 \%)$ & 0.047 \\
\hline Interferon alpha & $8(15.7 \%)$ & $6(75 \%)$ & $2(25 \%)$ & 0.694 \\
\hline Any interferon & $31(60.8 \%)$ & 24 (77.4 \%) & $7(22.6 \%)$ & 0.009 \\
\hline Ribavirin & 19 (37.5 \%) & $13(68.4 \%)$ & $6(13.6 \%)$ & 0.564 \\
\hline Antibiotics & 42 (82.4 \%) & $26(61.9 \%)$ & $16(38.1 \%)$ & 1.000 \\
\hline Hydrocortisone & $5(9.8 \%)$ & $2(40 \%)$ & $3(60 \%)$ & 0.348 \\
\hline Mycophenolate mofetil & $8(15.7 \%)$ & $8(100 \%)$ & $0(0 \%)$ & 0.019 \\
\hline ICU stay during admission & $19(37.3 \%)$ & $0(0 \%)$ & 19 (100\%) & 0.000 \\
\hline Extracorporeal Membrane Oxygenation & $10(19.6 \%)$ & $0(0 \%)$ & $10(100 \%)$ & 0.000 \\
\hline
\end{tabular}

one third of patients present with gastrointestinal symptoms [14]. Fever has been seen in $62-87 \%$ of patients, cough in 55-87\%, and gastrointestinal symptoms in 26-35\%. Seventy-six to $96 \%$ percent of patients have had comorbid illnesses, most commonly chronic renal failure, diabetes and heart disease [7-15]. This may be partially related to the epidemiology of increased disease transmission in healthcare settings rather than a true host risk factor. Laboratory findings have been nonspecific and consistent with other viral infections. Thrombocytopenia (75 \%) and lymphopenia (58 \%) have been commonly described in these patients [7, 9-13, 15]. Forty three percent had acute kidney injury [7, 11-13, 17] and 76-100\% had CXR abnormalities with bibasilar infiltrates as the most common finding $[8-13,15,18]$. The outcomes in these more severely ill patients remain poor. Between 50-90 \% required ICU care $[10,11,13,15]$ and $67-100 \%$ in the ICU setting required invasive ventilation for a median of $7-16$ days $[8,10,12]$. In addition to mechanical ventilation, several patients have received extracorpeal membrane oxygenation (ECMO) to support ventilation. From non-randomized data from the World Health Organization, five out of six patients receiving ECMO died [9]. Fifty-eight to $75 \%$ required renal replacement therapy $[11,12,17]$ and $30-60 \%$ of hospitalized patients died [7-15]. The severity of illness can be partially explained by the widespread lung disease caused by MERS-CoV and it appears that mortality in those patients requiring intensive care is extremely high. Although no autopsy data is available, in explanted lung, infection with

Table 2 Multivariable analysis of treatments and their impact on mortality

\begin{tabular}{lccc}
\hline & Odds ratio & Confidence interval & $P$ value \\
\hline Beta interferon & 0.68 & $0.04-10.28$ & 0.778 \\
Alpha interferon & 0.47 & $0.02-10.38$ & 0.630 \\
Hydrocortisone & 2.92 & $0.13-63.62$ & 0.495 \\
Ribavirin & 0.66 & $0.04-12.36$ & 0.779 \\
Modified APACHE 2 score & 1.60 & $1.18-2.17$ & 0.002 \\
\hline
\end{tabular}

MERS-CoV causes widespread infection and alveolar disease $[19,20]$.

The clinical features in our cohort similarly also show a high proportion of patients with fever (96\%) and cough (80.4\%) shortness of breath (90\%), and almost one third of patients $(29.4 \%)$ with gastrointestinal symptoms. Our cohort consisted of ill patients with hypotension (15.7\%), tachypnea (76.9\%) and hypoxia (33 \%). Thirty seven percent required ICU care and 10 patients received ECMO. Similar to previous results, all of the patients who received ECMO died [9].

There is no known effective treatment for MERS CoV. Many compounds have been screened in vitro for possible activity against this coronavirus [21-24], however, the in vivo efficacy has not been subjected to clinical investigation.

In vitro data suggests that MERS-CoV inhibits host interferon production through various molecular pathways [25-30] mycophenic acid, the active agent of prodrug mycophenolate mofetil, and cyclosporine strongly inhibit MERS coronavirus in human and monkey cell lines even more so than they inhibit SARS coronavirus [24, 31-33]. Interferon alpha and interferon beta reduce MERS coronavirus replication in explanted lung tissue [19]. In vivo, comparing host response in two patients with MERS coronavirus and differing outcomes, the patient who was able to clear MERS CoV infection was able to mount an interferon response and the patient who died had low levels of interferon alpha suggesting a

Table 3 Univariable analysis of the impact of severity of illness on treatments administered

\begin{tabular}{lclc}
\hline & Risk association & Confidence interval & $P$ value \\
\hline Beta interferon & -4.62 & $-8.40,-0.84$ & 0.018 \\
Alpha interferon & -1.24 & $-6.71,4.24$ & 0.652 \\
Ribavirin & 0.78 & $-3.34,4.90$ & 0.704 \\
Viral treatment & -5.98 & $-9.73,-2.23$ & 0.002 \\
Mycophenolate mofetil & -7.91 & $-12.90,-2.91$ & 0.003 \\
Hydrocortisone & 3.03 & $-3.62,9.68$ & 0.364 \\
\hline
\end{tabular}


therapeutic role for interferon [34]. The combination of interferon alpha and ribavirin has been used successfully in rhesus monkeys infected with MERS coronavirus [35], and in a few small case series [36-38]. Beta-interferon seems to be an even more potent inhibitor of MERS coronavirus in vitro [19] [24, 31-33]. One small study with exceptionally high mortality rates using interferon beta for treatment found no difference in mortality between interferon beta use and interferon alpha use [39]. Our data, albeit from a retrospective cohort support the findings that interferon beta is associated with a decrease in mortality.

There are limited data on the efficacy of treatment regiments for this virulent disease. We present data from a retrospective cohort of ill patients with Mers-CoV and the results of the evaluation of the clinical efficacy of beta interferon beta, alpha interferon, ribavirin and mycophenolate mofetil in addition to routine supportive care. Forty five percent of patents (23 patients) received interferon beta and in this cohort, sixteen percent of patients received interferon alpha (8 patients) and $37 \%$ of patients ( 9 patients) received ribavirin, either in conjunction with interferon alpha or interferon beta, and 8 patient received mycophenolate mofetil. Patients receiving beta interferon and mofetil had improved survival, however this was confounded by the severity of illness on presentation for beta interferon. All of the patients who received mycophenolate mofetil survived however because of the small number, we could not analyze the independent efficacy of mycophenolate mofetil.

While this is a relatively large series of MERS-CoV cases, the primary limitation of our study is that it is a retrospective review of cases and not a randomized trial and thus subject to confounding as seen in our cohort. We used a modified APACHE 2 score without all of the clinical variables, which may have underestimated the association of severity of illness with reduced survival. Importantly, the mortality in patients receiving additional therapies that modulate the immune response was low. All of the eight patients who received mycophenolate mofetil in our study survived. Hence, it may be reasonable to further study this agent in controlled trials.

\section{Conclusions}

This observational study investigates novel treatment options like beta interferon and mycophenolate mofetil for MERS-CoV in humans which have in vitro activity. Our cohort demonstrated severity of illness is an important effect modifier and needs to be considered in evaluating novel agents. To better assess the efficacy of these therapies, international prospective randomized trials with adequate numbers of patients are needed to further evaluate the impact of these treatments in addition to routine supportive care when compared to other treatment options.

\section{Ethics approval}

This study was reviewed and approved by Johns Hopkins University Institutional Review Board and the Directorate of Health Affairs.

\section{Availability of data and materials}

Data supporting the findings are in the manuscript, additional data available upon request.

\section{Abbreviations}

AIDS: acquired immune deficiency syndrome; ALT: alanine transaminase; APACHE 2: acute physiologic and chronic health evaluation; AST: aspartate aminotransferase; CXR: chest $x$ ray; ECMO: extracorporeal membrane oxygenation; ICU: intensive care unit; LDH: lactate dehydrogenase; MERS CoV: Middle Eastern Respiratory Syndrome coronavirus; PCR: polymerase chain reaction.

\section{Competing interests}

The authors declare that they have no competing interests.

\section{Authors' contributions}

MA conceived of the study, participated in its design and helped draft the manuscript. KA participated in data collection and analysis, and reviewed the manuscript. YG participated in data collection and analysis, and reviewed the manuscript. AA participated in data collection and analysis, and reviewed the manuscript. FS participated in data collection and analysis, and reviewed the manuscript. AA participated in data collection and analysis, and reviewed the manuscript. MB participated in data collection and analysis, and reviewed the manuscript. TMP participated in the design and analysis as well as the writing of the manuscript. DV participated in the statistical analysis of the study. GS helped analyze the data and write the manuscript. All authors read and approved the final manuscript.

\section{Acknowledgements}

There are no acknowledgements.

\section{Funding}

There was no external funds provided for this project.

\section{Author details}

${ }^{1}$ King Fahd General Hospital, Jeddah, Kingdom of Saudi Arabia. ${ }^{2}$ Department of Medicine, Division of General Internal Medicine, The Johns Hopkins University, School of Medicine, Baltimore, Maryland, USA. ${ }^{3}$ Department of Internal Medicine, Division of Infectious Diseases, The Johns Hopkins University, School of Medicine, Baltimore, 21224 Maryland, USA.

Received: 30 September 2015 Accepted: 31 March 2016 Published online: 21 April 2016

\section{References}

1. Peiris JS, Yuen KY, Osterhaus AD, Stöhr K. The severe acute respiratory syndrome. N Engl J Med. 2003;349(25):2431-41.

2. Zaki AM, van Boheemen $S$, Bestebroer TM, Osterhaus AD, Fouchier RA Isolation of a novel coronavirus from a man with pneumonia in Saudi Arabia. N Engl J Med. 2012;367(19):1814-20.

3. Wise J. Patient with new strain of coronavirus is treated in intensive care at London hospital. BMJ. 2012;345:e6455.

4. Pollack MP, Pringle C, Madoff LC, Memish ZA. Latest outbreak news from ProMED-mail: novel coronavirus - Middle East. Int J Infect Dis. 2013;17(2): e143-4.

5. de Groot RJ, Baker SC, Baric RS, Brown CS, Drosten C, Enjuanes L, Fouchier RA, Galiano M, Gorbalenya AE, Memish ZA, Perlman S, Poon LL, Snijder EJ, Stephens GM, Woo PC, Zaki AM, Zambon M, Ziebuhr J. Middle East respiratory syndrome coronavirus (MERS-CoV): announcement of the Coronavirus Study Group. J Virol. 2013;87(14):7790-2. 
6. WHO summary http://www.who.int/csr/don/4-january-2016-mers-saudiarabia/en/accessed 12 Dec 2015.

7. Memish ZA, Zumla Al, Al-Hakeem RF, Al-Rabeeah AA, Stephens GM. Family cluster of Middle East respiratory syndrome coronavirus infections. N Engl J Med. 2013;368(26):2487-94.

8. Assiri A, McGeer A, Perl TM, Price CS, Al Rabeeah AA, Cummings DA Alabdullatif ZN, Assad M, Almulhim A, Makhdoom H, Madani H, Alhakeem R, Al-Tawfiq JA, Cotten M, Watson SJ, Kellam P, Zumla Al, Memish ZA; KSA MERS-CoV Investigation Team. Hospital outbreak of Middle East respiratory syndrome coronavirus. N Engl J Med. 2013;369(5):407-16.

9. Who Mers-Cov Research Group. State of Knowledge and Data Gaps of Middle East Respiratory Syndrome Coronavirus (MERS-CoV) in Humans. PLoS Curr. 2013;12:5.

10. Assiri A, Al-Tawfiq JA, Al-Rabeeah AA, Al-Rabiah FA, Al-Hajjar S, Al-Barrak A, Flemban H, Al-Nassir WN, Balkhy HH, Al-Hakeem RF, Makhdoom HQ, Zumla Al, Memish ZA. Epidemiological, demographic, and clinical characteristics of 47 cases of Middle East respiratory syndrome coronavirus disease from Saudi Arabia: a descriptive study. Lancet Infect Dis. 2013;13(9):752-61.

11. Saad M, Omrani AS, Baig K, Bahloul A, Elzein F, Matin MA, Selim MA, Mutairi MA, Nakhli DA, Aidaroos AY, Sherbeeni NA, Al-Khashan HI, Memish ZA, Albarrak AM. Clinical aspects and outcomes of 70 patients with Middle East respiratory syndrome coronavirus infection: a single-center experience in Saudi Arabia. Int J Infect Dis. 2014;29:301-6.

12. Arabi YM, Arifi AA, Balkhy HH, Najm H, Aldawood AS, Ghabashi A, Hawa H, Alothman A, Khaldi A, Al Raiy B. Clinical course and outcomes of critically ill patients with Middle East respiratory syndrome coronavirus infection. Ann Intern Med. 2014;160(6):389-97.

13. Al-Abdallat MM, Payne DC, Alqasrawi S, Rha B, Tohme RA, Abedi GR, Al Nsour M, Iblan I, Jarour N, Farag NH, Haddadin A, Al-Sanouri T, Tamin A, Harcourt JL, Kuhar DT, Swerdlow DL, Erdman DD, Pallansch MA, Haynes LM, Gerber SI; Jordan MERS-CoV Investigation Team. Hospital-associated outbreak of Middle East respiratory syndrome coronavirus: a serologic, epidemiologic, and clinical description. Clin Infect Dis. 2014;59(9):1225-33.

14. Memish ZA, Zumla Al, Assiri A. Middle East respiratory syndrome coronavirus infections in health care workers. N Engl J Med. 2013;369(9):884-6.

15. Al-Tawfiq JA, Hinedi K, Ghandour J, Khairalla H, Musleh S, Ujayli A, Memish ZA. Middle East respiratory syndrome coronavirus: a case-control study of hospitalized patients. Clin Infect Dis. 2014;59(2):160-5.

16. Knaus WA et al. APACHE II: a severity of disease classification system. Crit Care Med. 1985;13(10):818-29.

17. Eckerle I, Müller MA, Kallies S, Gotthardt DN, Drosten C. In-vitro renal epithelial cell infection reveals a viral kidney tropism as a potential mechanism for acute renal failure during Middle East Respiratory Syndrome (MERS) Coronavirus infection. J Virol. 2013;10:359. doi:10.1186/1743-422X-10-359.

18. Ajlan AM, Ahyad RA, Jamjoom LG, Alharthy A, Madani TA. Middle East respiratory syndrome coronavirus (MERS-CoV) infection: chest $C T$ findings. AJR Am J Roentgenol. 2014;203(4):782-7.

19. Chan RW, Chan MC, Agnihothram S, Chan LL, Kuok DI, Fong JH, Guan Y, Poon LL, Baric RS, Nicholls JM, Peiris JS. Tropism of and innate immune responses to the novel human betacoronavirus lineage $C$ virus in human ex vivo respiratory organ cultures. J Virol. 2013;87(12):6604-14.

20. Hocke AC, Becher A, Knepper J, Peter A, Holland G, Tönnies M, Bauer TT, Schneider P, Neudecker J, Muth D, Wendtner CM, Rückert JC, Drosten C, Gruber AD, Laue M, Suttorp N, Hippenstiel S, Wolff T. Emerging human middle East respiratory syndrome coronavirus causes widespread infection and alveolar damage in human lungs. Am J Respir Crit Care Med. 2013;188(7):882-6.

21. Dyall J, Coleman CM, Hart BJ, Venkataraman T, Holbrook MR, Kindrachuk J, Johnson RF, Olinger GG Jr, Jahrling PB, Laidlaw M, Johansen LM, LearRooney CM, Glass PJ, Hensley LE, Frieman MB. Repurposing of clinically developed drugs for treatment of Middle East respiratory syndrome coronavirus infection. Antimicrob Agents Chemother. 2014;58(8):4885-93.

22. Adedeji AO, Singh $K$, Kassim A, Coleman CM, Elliott R, Weiss SR, Frieman MB, Sarafianos SG. Evaluation of SSYA10-001 as a replication inhibitor of severe acute respiratory syndrome, mouse hepatitis, and Middle East respiratory syndrome coronaviruses. Antimicrob Agents Chemother. 2014;58(8):4894-8.

23. de Wilde AH, Jochmans D, Posthuma CC, Zevenhoven-Dobbe JC, van Nieuwkoop S, Bestebroer TM, van den Hoogen BG, Neyts J, Snijder EJ. Screening of an FDA-approved compound library identifies four smallmolecule inhibitors of Middle East respiratory syndrome coronavirus replication in cell culture. Antimicrob Agents Chemother. 2014;58(8):4875-84.
24. Chan JF, Chan KH, Kao RY, To KK, Zheng BJ, Li CP, Li PT, Dai J, Mok FK, Chen $\mathrm{H}$, Hayden FG, Yuen KY. Broad-spectrum antivirals for the emerging Middle East respiratory syndrome coronavirus. J Infect. 2013;67(6):606-16.

25. Gralinski LE, Baric RS. Molecular pathology of emerging coronavirus infections. J Pathol. 2015;235(2):185-95.

26. Niemeyer D, Zillinger T, Muth D, Zielecki F, Horvath G, Suliman T, Barchet W, Weber F, Drosten C, Müller MA. Middle East respiratory syndrome coronavirus accessory protein $4 \mathrm{a}$ is a type I interferon antagonist. J Virol. 2013;87(22):12489-95.

27. Menachery VD, Eisfeld AJ, Schäfer A, Josset L, Sims AC, Proll S, Fan S, Li C, Neumann G, Tilton SC, Chang J, Gralinski LE, Long C, Green R, Williams CM, Weiss J, Matzke MM, Webb-Robertson BJ, Schepmoes AA, Shukla AK, Metz TO, Smith RD, Waters KM, Katze MG, Kawaoka Y, Baric RS. Pathogenic influenza viruses and coronaviruses utilize similar and contrasting approaches to control interferon-stimulated gene responses. MBio. 2014; 5(3):e01174-14.

28. Yang X, Chen X, Bian G, Tu J, Xing Y, Wang Y, Chen Z. Proteolytic processing, deubiquitinase and interferon antagonist activities of Middle East respiratory syndrome coronavirus papain-like protease. J Gen Virol. 2014; 95(Pt 3):614-26.

29. Yang Y, Zhang L, Geng H, Deng Y, Huang B, Guo Y, Zhao Z, Tan W. The structural and accessory proteins M, ORF 4a, ORF 4b, and ORF 5 of Middle East respiratory syndrome coronavirus (MERS-CoV) are potent interferon antagonists. Protein Cell. 2013;4(12):951-61.

30. Matthews KL, Coleman CM, van der Meer Y, Snijder EJ, Frieman MB. The ORF4b-encoded accessory proteins of Middle East respiratory syndrome coronavirus and two related bat coronaviruses localize to the nucleus and inhibit innate immune signalling. J Gen Virol. 2014;95(Pt 4):874-82.

31. Kindler E, Jónsdóttir HR, Muth D, Hamming OJ, Hartmann R, Rodriguez R, Geffers R, Fouchier RA, Drosten C, Müller MA, Dijkman R, Thiel V. Efficient replication of the novel human betacoronavirus EMC on primary human epithelium highlights its zoonotic potential. MBio. 2013;4(1):e00611-2.

32. de Wilde AH, Raj VS, Oudshoorn D, Bestebroer TM, van Nieuwkoop S, Limpens RW, Posthuma CC, van der Meer Y, Bárcena M, Haagmans BL, Snijder EJ, van den Hoogen BG. MERS-coronavirus replication induces severe in vitro cytopathology and is strongly inhibited by cyclosporin A or interferon-a treatment. J Gen Virol. 2013:94(Pt 8):1749-60.

33. Hart BJ, Dyall J, Postnikova E, Zhou H, Kindrachuk J, Johnson RF, Olinger GG $J$ r, Frieman MB, Holbrook MR, Jahrling PB, Hensley L. Interferon- $\beta$ and mycophenolic acid are potent inhibitors of Middle East respiratory syndrome coronavirus in cell-based assays. J Gen Virol. 2014;95(Pt 3):571-7.

34. Faure E, Poissy J, Goffard A, Fournier C, Kipnis E, Titecat M, Bortolotti P, Martinez L, Dubucquoi S, Dessein R, Gosset P, Mathieu D, Guery B. Distinct immune response in two MERS-CoV-infected patients: can we go from bench to bedside? PLoS One. 2014;9(2):e88716.

35. Falzarano D, de Wit E, Rasmussen AL, Feldmann F, Okumura A, Scott DP, Brining D, Bushmaker T, Martellaro C, Baseler L, Benecke AG, Katze MG, Munster $\mathrm{VJ}$, Feldmann $\mathrm{H}$. Treatment with interferon- $\mathrm{a} 2 \mathrm{~b}$ and ribavirin improves outcome in MERS-CoV-infected rhesus macaques. Nat Med. 2013; 19(10):1313-7.

36. Omrani AS, Saad MM, Baig K, Bahloul A, Abdul-Matin M, Alaidaroos AY, Almakhlafi GA, Albarrak MM, Memish ZA, Albarrak AM. Ribavirin and interferon alfa-2a for severe Middle East respiratory syndrome coronavirus infection: a retrospective cohort study. Lancet Infect Dis. 2014;14(11):1090-5.

37. Khalid M, Al Rabiah F, Khan B, Al Mobeireek A, Butt TS, Al ME. Ribavirin and interferon (IFN)-alpha-2b as primary and preventive treatment for Middle East respiratory syndrome coronavirus (MERS-CoV): a preliminary report of two cases. Antivir Ther. 2015;20(1):87-91.

38. Al-Tawfiq JA, Momattin $\mathrm{H}$, Dib J, Memish ZA. Ribavirin and interferon therapy in patients infected with the Middle East respiratory syndrome coronavirus: an observational study. Int J Infect Dis. 2014;20:42-6.

39. Shalhoub S, Farahat F, Al-Jiffri A, Simhairi R, Shamma O, Siddiqi N, Mushtaq A. IFN-a2a or IFN- $\beta 1$ a in combination with ribavirin to treat Middle East respiratory syndrome coronavirus pneumonia: a retrospective study. J Antimicrob Chemother. 2015;70(7):2129-32. 